\title{
Correction to: Shared school transportation: determinants of carpooling as children's school travel mode in California
}

\section{Rezwana Rafiq ${ }^{1}$. Suman Kumar Mitra ${ }^{1}$ (D)}

Published online: 3 January 2019

(c) Springer Science+Business Media, LLC, part of Springer Nature 2019

\section{Correction to: Transportation}

\section{https://doi.org/10.1007/s11116-018-9942-z}

In the online published article, in Fig. 2 a value is missing in column 4. The correct figure is given in this correction. The original article has been corrected.

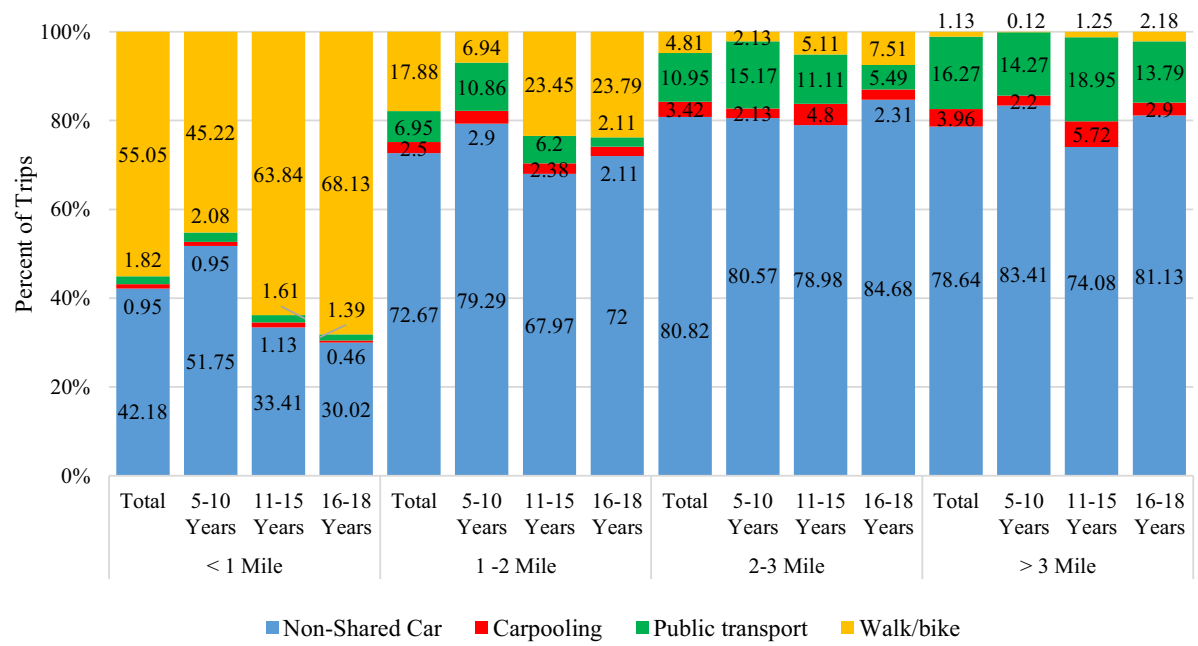

Fig. 2 Mode of arrival to school by distance and age groups, 2012 CHTS

The original article can be found online at https://doi.org/10.1007/s11116-018-9942-z.

Suman Kumar Mitra

skmitra@uci.edu

Rezwana Rafiq

rrafiq@uci.edu

1 Institute of Transportation Studies (ITS), University of California, Irvine, CA 92697-3600, USA 